\title{
O REENCONTRO DA CLÍNICA COM A METÁFORA
}

\author{
Valeska Zanello* \\ Francisco Martins
}

RESUMO. Desde a Idade Antiga houve uma consolidação de características que se tornaram prementes no pensamento ocidental, entre as quais temos a busca da "clareza" das proposições e a verdade compreendida como correspondência (adequação). A metáfora, promotora de equívocos, deveria ser expulsa do pensamento sério e rigoroso, a saber, da filosofia e, posteriormente, das ciências em geral. A medicina, como ciência, comungou com estes pressupostos, que nela se fizeram presentes por meio da semiologia indicial. Não obstante, a metáfora retornou por meio do sofrimento dos pacientes, inscrita nos corpos: o sintoma histérico. Como calcanhar de Aquiles para a medicina, este sintoma provocou uma reviravolta no próprio procedimento clínico e em sua produção de saber, abrindo espaço para a qualificação do acontecimento de metáforas e, sobretudo, para a escuta do pathos humano. Neste artigo propomos um estudo teórico deste reencontro, apontando que nele houve a abertura da clínica para uma escuta diferenciada, trazida pela psicanálise.

Palavras-chave: Metáfora; psicologia clínica; semiologia.

\section{THE CLINIC'S RE-MEETING WITH THE METAPHOR}

\begin{abstract}
Since the Ancient Age, there has been a consolidation of characteristics which have become pressing in the Western thought. Among them, we have the search for the "clarity" of the propositions and the truth understood as a correspondence (adequacy). The metaphor, promoter of mistakes, should be expelled from the rigorous and serious thought, namely philosophy, and later on, from the sciences in general. The Medicine, as a science, has communed with those assumptions which were present in it through the indicial semiology. However, the metaphor has returned through the patients' suffering, inscribed on their bodies: the hysterical symptom. As the Achilles' heel for the medicine, that symptom has trigged a turnaround in the clinical procedures and in its production of knowledge, giving room to the qualification of the occurrence of metaphors and, especially, to the listening of the human pathos. In this article, we posit a theoretical study of that re-meeting, pointing out that there was in it the opening of the clinic for a differentiated listening, evoked by the psychoanalysis.
\end{abstract}

Key words: Metaphor; clinical psychology; semiology.

\section{LA REUNIÓN DE LA CLÍNICA CON LA METÁFORA}

RESUMEN. Desde la Edad Antigua, hubo una consolidación de características que se hicieron predominantes en el pensamiento occidental. Entre ellas, tenemos la búsqueda de la "nitidez" de las proposiciones y la verdad comprendida como correspondencia (adaptación). La metáfora, fomentadora de equívocos, debería ser "expulsada" del pensamiento serio y riguroso, ergo, de la filosofía, y posteriormente, de las ciencias en general. La medicina, como ciencia, comulgó con estas suposiciones que se hicieron presentes a través de la semiología indicial. Sin embargo, la metáfora retornó a través del sufrimiento de los pacientes, grabadas en los cuerpos: el síntoma histérico. Como el talón de Aquiles para la medicina, este síntoma provocó una revolución en el propio procedimiento clínico y en su producción del saber, abriendo espacio para la calificación de ocurrencia de metáforas y, sobre todo, para la escucha del pathos humano. En este artículo, proponemos un estudio teórico de este reencuentro, señalándolo como la apertura de la clínica para una escucha diferenciada, generada por el psicoanálisis.

Palabras-clave: Metáfora; psicología clínica; semiología.

Desde seus primórdios a filosofia se viu interpelada pela busca de verdade e de certezas universais. A linguagem, como característica distintivamente humana, deveria ser bem utilizada no

\footnotetext{
Psicóloga. Bacharel em Filosofia. Doutora em Psicologia. Professora Adjunta do Curso de Psicologia do IESB/ Brasília.

\# Psicólogo. Psicanalista. Professor do Departamento de Psicologia e do Programa de Pós-graduação em Psicologia Clínica da PUC-Rio.
} 
intuito de facilitar e promover tal busca. Trata-se do Logos enquanto racionalidade afirmada desde os gregos, tendo Aristóteles aqui um papel essencial. Vernant (1973) nos mostra que é apenas por volta do século VI a.C. que se dá a importante separação entre Mytho e Logos, isto é, a separação entre a palavra/ discurso e a realidade. $\mathrm{O}$ que sustenta tal diferenciação são as mudanças políticas que levam à afirmação da Polis. Se antes, com Parmênides, somos levados a pensar palavra e verdade como indissociáveis (o Ser é; a palavra advém de um escolhido, seja aqui o filósofo ou o aedo), isto é, um tipo de palavra que, ao nomear algo, está dizendo a coisa mesma; temos agora uma afirmação de uma palavra-diálogo, disponível aos guerreiros, desvinculada do compromisso com a verdade, a qual diz respeito a uma troca de ideias e a uma estratégia de luta. A palavra é assim dessacralizada, fazendo parte do próprio discurso poder dizer o que não é. É neste contexto que podemos compreender a preocupação de Aristóteles, mas antes dele, do próprio Platão, com o mau uso da palavra, sobretudo pelos sofistas. Para se dizer o que não é, deve-se poder diferenciar, ainda que em gradações diferentes, ser-coisa e ser-termo-dediscurso.

\begin{abstract}
São transformações que convergem para uma nova experiência de significação. A palavra é relativizada à medida que avança na autonomia com relação ao real. Ela não é mais presença absoluta, palavra realidade que flui da boca da divindade, do adivinho ou do poeta inspirado. Enquanto palavra humana que pertence a todos e a cada um, ela se torna cada vez mais circunscrita ao momento de sua enunciação. Ela depende de vários fatores circunstanciais para se fazer valer enquanto coisa verdadeira; isto é, sua eficácia, seu poder de realização, tende a se esvanecer na multiplicidade de variáveis que determinam o evento do discurso público. (Marques, 1990, p. 33)
\end{abstract}

Como apontamos, Aristóteles teve aqui um papel capital, pois foi o primeiro a romper o vínculo natural entre as palavras e as coisas (Garcia-Roza, 2001). A primeira definição oficial da metáfora também foi dada por ele, em sua Poética: "Metáfora é a transferência do nome de uma coisa para outra, ou do gênero para a espécie, ou da espécie para o gênero, ou de uma espécie para outra, ou por analogia" (Aristóteles, séc. IV a.c./ 1999, p. 63). Destacamos aqui as palavras "transferência" e "nome", pois elas dão origem a uma tradição que durará longo tempo e que compreende a metáfora como substituição de um nome próprio por um impróprio. A metáfora, por ser promotora de equivocidade, deveria ser evitada na busca do saber seguro da Filosofia: "se na discussão dialética tem que se evitar as metáforas, é óbvio que não há que se usar metáforas nem expressões metafóricas na definição" (Aristóteles, séc. IV a.c./ 1999, p. 63). Ele nos diz ainda que "em todos os casos em que um problema resulta difícil de atacar, tem que se supor que necessita de definição ou que há sido expresso multivocamente ou em sentido metafórico" (Aristóteles, séc. IV a.c./ 2005, p. 526). No entanto, a metáfora encontrará um papel importante, específico, em seu sistema filosófico.

Para ele, ainda que a metáfora tenha a mesma definição e estrutura, ela terá duas funções distintas: uma poética e uma retórica. Ambas não podem ser desvinculadas de seu sistema filosófico. Se para Platão o universal é ante re, para o Estagirita ele é in re, isto é, só chegamos a ele como fruto da abstração, ele constitui a substância segunda. Para Aristóteles, a natureza possui sua causa em si mesma (sua própria teleologia), mas o homem foge a esta regra: por um lado é marcado pela essência universal de homem, mas por outro, é páthico, isto é, possui um caráter de contingência, de um poder ser que não tem nenhuma necessidade. O pathos escapa ao conceito:

A planta, avançando inexoravelmente para seu destino e realizando-o biologicamente, não poderia, pois, ter paixão. $\mathrm{O}$ pathos tornou-se assim paixão, expressão da natureza humana, da liberdade (...). A paixão escapara ao logos, centrado no caráter apodítico proveniente da identidade redutora do sujeito; assim se compreende o caráter ameaçador e irracional da paixão por um logos definido apenas pela apodicidade. $\mathrm{O}$ dualismo, que ressurge do aspecto inassimilável do pathos à substância, vai opor a ordem humana e a ordem natural (...). A paixão é a alternativa (...). Ela é, por isso mesmo, o lugar do Outro, da possibilidade diferente do que somos afinal; o individual ao universal indiferenciado (...). A oponibilidade que une e desune os homens é precisamente o passional, a contingência que os libera ao mesmo tempo que pode entregálos ao que os destrói e ao que os subjuga. (Meyer, 2000, p. XXXV)

É neste contexto que precisamos compreender tanto a retórica quanto a poética (e o papel da metáfora nelas), pois de certa maneira ambas dizem respeito a este traço distintivo de contingência no ser humano. Aristóteles admite as paixões, mas prefere a força apodítica do saber científico. A Retórica se 
inscreve no jogo dos contrários do campo passional, ocupa-se mesmo destas oposições. O que o filósofo busca mostrar aí é que as paixões "constituem um teclado no qual o bom orador toca para convencer" (Meyer, 2000, p. XLI). Em outras palavras, a metáfora servirá como instrumento para tocar a alma do ouvinte, justamente naquilo que ela tem de caráter contingencial.

A retórica é assim uma técnica da eloquência: se o pathos é o lugar da contingência, a retórica se inscreve na dupla possibilidade - de uso selvagem da palavra e da ambição de apreender por meio de uma técnica especial sua perigosa potência (Ricoeur, 2000) - isto é, entre o uso sofístico e o uso adestrado pela filosofia. Neste sentido, Aristóteles é um autor fundamental para o nosso tema, pois, para ele, a metáfora se inscreve ainda em todo um programa filosófico. É a partir dessa época que a metáfora terá, via prodigalização da retórica, um processo longo de exclusão da filosofia, assim como uma amputação de todo seu potencial. A metáfora perde a partir daqui sua inscrição em um programa filosófico e passa a ser considerada como mera figura estilística de linguagem, um adorno fútil e extremamente perigoso para um discurso que busque a verdade.

Apel (2000) aponta assim que já em Aristóteles delineia-se a questão do problema de uma filosofia "linguístico-analítica":

\begin{abstract}
Trata-se por um lado, de rastrear e desmascarar as fontes que induzem o pensamento humano a erros que estão baseadas sobre mal-entendidos da função linguística, e, por outro lado, de investigar profundamente essa mesma função linguística (as regras sintáticas e semânticas do uso dos signos) ao ponto que a polissemia da linguagem cotidiana não se interponha mais ao avanço do acordo mútuo científico (Apel, 2000, p. 334).
\end{abstract}

Para Apel, a abstração da dimensão pragmática do discurso está explícita na separação entre poética e retórica de um lado e lógica da linguagem de outro (ou entre poesia e filosofia; Apel, 2000). Neste sentido, o autor cita um comentário de Ammonius que vale a pena reproduzir aqui:

Já que o discurso tem uma dupla relação - tal como demonstrou Teofrasto (discípulo de Aristóteles)- uma com os ouvintes para os quais ela significa algo, e outra com as coisas sobre as quais o falante relata algo para os ouvintes- surgem a poética e a retórica, em vista da relação com os ouvintes; mas em vista da relação do discurso com as coisas, o filósofo é responsável por refutar as coisas falsas e comprovar as verdadeiras (citado por Apel, 2000, p. 333).

É no âmbito da proposição que se afirma a verdade e a falsidade. Segundo Foss (1965), a proposição está para a filosofia como a metáfora está para a poesia. É neste contexto que a metáfora se vê expulsa, como já apontamos, como um elemento estranho ao pensamento tido como sério e rigoroso. A proposição é o próprio coração da lógica. Aristóteles postula para ela três princípios lógicos fundamentais, a saber:

1. a identidade: $\mathrm{a}=\mathrm{a}$;

2. a contradição: é impossível que o mesmo atributo pertença e não pertença ao mesmo tempo ao mesmo sujeito e sob a mesma relação (Aristóteles, séc. IV a.c./1991); isto é, algo não pode ser p e não-p, ao mesmo tempo;

3. o terceiro excluído: não há meio termo entre dois contrários, por exemplo entre q e não-q: se a proposição q é verdadeira, então a proposição não-q deve ser necessariamente falsa (Aristóteles, séc. IV a.c./1991).

Trata-se aqui não apenas de uma questão linguística, do que pode ou não ser dito com sentido, mas de uma questão ontológica, através da qual a natureza da realidade é pensada em sua relação com o ser e o discurso. Segundo Rorty,

Em particular, a tradição sugeriu que as palavras particulares que nós usamos são desimportantes. Desde quando a filosofia ganhou a disputa com a poesia, era o pensamento que contava - a proposição, algo que muitas sentenças em muitas línguas expressam igualmente bem. Se uma sentença é falada ou escrita, se ela contém palavras gregas ou alemãs ou inglesas, não importa muito, segundo a visão filosófica tradicional. Pois as palavras são meros veículos para algo menos frágil e transitório do que as marcas e os sons. Os filósofos sabem que o que importa é a verdade literal, não a escolha de fonemas, e certamente não as metáforas. O literal é duradouro e confere poder. O metafórico - sobre o qual não podemos nem arguir, nem justificar, e para o qual não se pode encontrar nenhuma paráfrase incontroversa - é impotente. Ele passa e não deixa nenhum traço (Rorty, 1999, p. 51-52).

Afirma-se, portanto, uma noção especular entre linguagem e realidade, entre proposição e mundo, 
situando-se a verdade como correspondência entre ambos (Rorty, 1994).

Esta busca de uma linguagem clara e especular (através da qual representaríamos a realidade) passou por vários percalços e acabou por desembocar, segundo Apel (2000), na construção de uma linguagem formal, tendo como exemplo apical aquela realizada por Frege e desenvolvida e refinada por Wittgenstein no seu Tractatus Logico-Philosophicus (1994). Nesta obra, característica da primeira fase de seu pensamento, o filósofo postula a existência de uma relação isomórfica entre linguagem e mundo ${ }^{1}$, sendo que a linguagem ordinária disfarçaria esta isomorfia, surgindo daí a necessidade de uma linguagem formal. A cada proposição deveria relacionar-se um estado de coisas possíveis (afirmação da semântica). Ainda que Wittgenstein tenha trazido o plano do sentido para a sintaxe, ou seja, para um plano anterior à avaliação do verdadeiro ou falso, comunga ainda, em sua pressuposição, com a metáfora especular linguagem/mundo ${ }^{2}$. Apontamos, no entanto, que o próprio autor reviu sua posição, ao se deparar especificamente com o problema das cores (Wittgenstein, 1995), isto é, com a necessidade de quantificar as matizes de uma mesma cor e representá-las na linguagem formal. Daqui surgiu a reviravolta, ou a famosa linguistic turn, da qual o autor é um bom paradigma. Foi na segunda fase de seu pensamento, ao escrever suas Investigações Filosóficas (Wittgenstein, 1991), que o filósofo afirmou a necessidade da pragmática, a ideia de que a linguagem não apenas representa o mundo, mas faz muitas outras coisas.

Apontamos assim a afirmação na história da filosofia em geral (até o começo da filosofia contemporânea), da proposição como peça-chave da linguagem representativa do mundo. Teríamos, desta maneira, que a um nome deveria corresponder um objeto (de preferência com biunivocidade, justamente para evitar o equívoco) e a uma proposição um fato do mundo, ou da realidade:

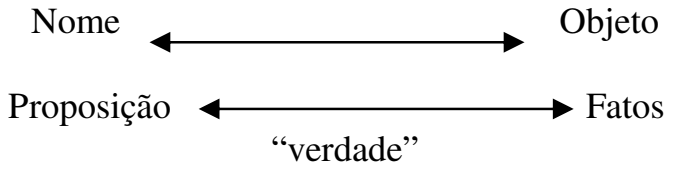

\footnotetext{
A proposição diria não o que o mundo é, mas como ele é.

2 Trazer o sentido para um plano anterior do verdadeiro e do falso implica em dizer que posso formar uma proposição que tenha sentido, ainda que seja falsa. Por exemplo, quando digo 'a grama é rosa', tenho uma proposição falsa para o nosso planeta, este mundo, mas poderia haver um mundo possível no qual esta proposição fosse o caso. $\mathrm{O}$ importante é que, para dizer que algo é verdadeiro ou falso, devo antes entendê-lo, isto é, deve ter sentido. O sentido seria a própria possibilidade de figurar o mundo.
}

Se a proposição representa "a existência e a inexistência dos estados de coisas" (Wittgenstein, 1994, p. 177), então "a totalidade das proposições verdadeiras é toda a ciência natural (ou a totalidade das ciências naturais)".

Trata-se agora de pensar o que deste projeto racional logrou encontrar lugar no pensar e fazer médicos, isto é, como a demarche filosófica se fez presente na semiologia científica da medicina. Nosso intuito é contextualizar a origem de Freud, para compreender a radicalidade de sua novidade clínica, através da afirmação de um campo humano essencialmente páthico, situando na abertura desta radicalidade o próprio encontro com a metáfora (ainda que em "negativo", "muda", como enigma inscrito no corpo das pacientes).

\section{SEMIOLOGIA: A MEDICINA E O PENSAR SINDRÔMICO INDICIAL}

De acordo com Martins (2003), a medicina pósSydenham se caracteriza, do ponto de vista semiológico, por um proceder sindrômico, isto é, visa a construir, detectar e prognosticar síndromes. Estas nada mais seriam que um conjunto estável de signos clínicos, sobretudo aqueles característicos (típicos) e diferenciadores da doença (patognomônicos).

O médico, em sua atividade clínica, acaba assim por buscar, no relato do paciente, signos, sinais e sintomas que perfazem a síndrome, apontando esta para a doença que presumivelmente o paciente tem, bem como para seu prognóstico. A ênfase na escuta do médico se dá, portanto, sobre o predicado daquilo que o paciente diz, sendo a linguagem valorizada não em sua plenitude, mas como objeto de descrição a facilitar sua tarefa. Vemos aqui a concepção de comunicação que se faz presente na clínica médica: o modelo que tem como metáfora de base o telégrafo. Segundo este modelo, entre um emissor e um receptor há uma mensagem, que circula entre as duas partes, e um código, que permite a tradução em signos das ideias transmitidas pelas mensagens (Meunier, 1994). Devese assim evitar o "ruído", que justamente seria representado, por exemplo, pelas metáforas. $\mathrm{O}$ paciente deve evitá-las, pois não proporcionam nenhum saber específico, relacionando-se mais com sua subjetividade (causadora de equívocos). Esta última não interessa ao médico cientista, pois este busca, como já dissemos, a fiabilidade e a univocidade de signos que apontem indicialmente para síndromes universais. Vemos aqui, desde já, uma reprodução de um modo de pensar marcado pela filosofia, tal qual 
apresentamos há pouco. Teríamos assim o seguinte esquema:

Filosofia: linguagem $\longrightarrow$ Estados de coisas no mundo (proposição)

Medicina: Síndromes, signos $\longrightarrow$ Doença e sintomas ÍNDICES

A medicina teria ainda como marcas de seu procedimento semiológico as seguintes características (Martins, 2003):

- ênfase no descritivismo, havendo uma preferência pelos termos constatativos por sua capacidade de serem verdadeiros ou falsos - por exemplo, "dói aqui, na altura do estômago", mas não "estou com dor nas passarinhas" ou "estou com dor de "cotovelo",

- a verdade continua a ser compreendida como uma boa adequação entre a síndrome e a doença da qual padece o paciente, por isso,

o conceito de referência é essencial para a qualificação da prática clínica tal como ela é exercida pela maioria dos médicos, uma vez que o diagnóstico é, na maioria da vezes, o objetivo a ser alcançado. Todo esse esforço de relacionar os signos diretamente aos seus referentes se funda em uma concepção um tanto ingênua do que seja a linguagem e a realidade. A realidade seria o equivalente a uma coisa (res) a ser nomeada logo que revelada através dos processos de diagnose. Como é sabido, a ideia principal consiste em encontrar um termo para cada dado do real, de forma a criar uma relação uniforme e isonômica entre linguagem (os nomes) e a realidade (as coisas) (Martins, 2003, p. 42);

a) hipervalorização do visível em detrimento do "invisível", isto é, valoriza-se o corpo enquanto Korp, res extensa, e não o corpo enquanto Leib, corpo vivido imaginário e simbólico. Aqui a metáfora do olhar, característica do pensamento ocidental se faz presente tanto na qualificação da fala que deve representar algo (metáfora especular), como no olhar físico, do corpo como um objeto;

b) busca da univocidade, isto é, de signos que apontem caracteristicamente para síndromes universais. Um bom signo é o que permite diferenciar uma doença da outra (assim como um nome deveria, no projeto filosófico, diferenciar uma coisa de outra);

c) ser denominadora;

d) substantivar o corpo e a fala (transformar ambos em res); e) Possuir um modo de proceder indicial, deixando de lado o aspecto icônico e simbólico.

Recorrendo-se aos procedimentos acima apontados, na busca da objetivação da síndrome, a atividade do clínico acaba por produzir um "lixo semiológico", "constituído principalmente por tudo aquilo que é subjetivo, intersubjetivo, ou mesmo objetivo, mas que não interessa para o diagnóstico. Interessante notar que os signos do tipo ícones e símbolos são, via de regra, identificados como boa parte deste lixo" (Martins, 2003, p. 96).

Esta última questão toca diretamente à metáfora, pois esta é marcada por uma dimensão da imagem (ícone) e da palavra (símbolo), sendo definida por alguns como ícone verbal. Segundo Verhaegen (1994), a metáfora, juntamente com a imagem e o diagrama, seria um ícone na Phaneroscopia de Peirce, ou seja, ela seria marcada pela questão da primeiridade e da aisthesis. A metáfora falada, ou verbal, diferenciar-se-ia da metáfora visual por, apesar de ser um ícone, relacionar-se mais diretamente ao símbolo. De acordo com o autor, é a capacidade de confusão de signos que é fundamental na metáfora: ela se utilizaria tanto da imagem como do diagrama, criando um amálgama destes universos num signo único, criando ou produzindo relações de similitude. A metáfora faz parte do lixo semiológico médico, assim como o fazia do lixo filosófico.

Além da metáfora, segundo Martins (2003), na prática clínica são também esquecidas a enunciação em ato (o processo de semiosis) e a própria pergunta pelo ser do doente (não se sai da ênfase do ter o sintoma). Há, portanto, uma desqualificação do próprio sujeito, um desconhecimento daquilo que nele se faz de mais humano e páthico. Trata-se, na medicina, de salvar e consertar o corpo-máquina ${ }^{3}$.

Entretanto, como destaca Martins (2003, p. 68),

a palavra é não só expressão da atividade cerebral, mas também de projeto e realização de vida. Mais ainda, o querer dizer passa pela mediação social, mas é ancorada na profundidade do corpo próprio. O corpo próprio é, por isso, um corpo simbolizado, constituído também pela linguagem. $\mathrm{O}$ braço

3 Segundo Descartes, em seu Discurso sobre o Método, teríamos dois tipos de res: a extensa e a cogitans. O corpo seria res extensa, um corpo máquina. Tal ideia-metáfora se infiltrou de modo maciço em nossa cultura e não sem consequências sérias e importantes. Como exemplo, a morte em massa de animais que são criados somente para o abate, pois estes já que não tem res cogitans, são apenas corpos-máquinas (res extensa). Ver RENÉ DESCARTES. Discurso sobre o método. São Paulo: Martin Claret, 2000. 
direito e o esquerdo não são somente os membros superiores. Um e outro se diferenciaram a tal ponto que a linguagem ordinária utilizará o termo 'braço direito' para designar alguém de confiança. Da mesma maneira, as partes de cima, por exemplo, a cabeça, e as de baixo, como os pés, recebem tratamentos e significações diversas. "Ele perdeu a cabeça" ou "Ele dizia coisas sem pé nem cabeça". A clínica se verá atravessada por metáforas relativas ao corpo próprio advindas da linguagem ordinária do sujeito. A semiologia da medicina inteira é atravessada por estas determinações culturais marcadas por metáforas que refletem o modo de viver de cada grupo.

Buscando assim evitar o equívoco, a variabilidade e a plurivocidade dos signos, a medicina se vê diante do abandono do campo páthico, pois se o corpo orgânico é mais compartilhado universalmente, enquanto "máquina" fisiológica, não podemos dizer o mesmo do corpo psíquico (Vergote, 1981). No entanto, o doutor, o prático, o praticante clínico da medicina, não tem como escapar das desagradáveis queixas e sintomas que fogem dos livros e compêndios de sintomatologias e síndromes; isto é, por mais que a medicina, enquanto ciência, queira se fundar não nas diferenças culturais e mesmo individuais, mas em dados semiológicos estáveis e universais (metáfora de base: o heliotropo), mostra-se impossível evitar na prática do médico o aparecimento de queixas "estranhas" por parte de seus pacientes, chegando algumas a negar o próprio conhecimento anatômico que tanto teve que estudar para adquirir.

Então, o que faz o médico quando se depara com estas queixas, por exemplo, de uma "dor nas passarinhas"? Ou, "sou uma garrafa de água gasosa que foi sacolejada"? Ou ainda, como trata a cegueira, por parte de uma paciente, para cujo sintoma de não enxergar não encontra nenhuma causa anatômica? É a própria subversão do lixo embaixo do tapete semiológico. Trata-se ou de desqualificar o sofrimento do outro quando este não se traduz na anatomia, ou de repensar a própria clínica a partir daquilo mesmo que foi descartado: o pathos humano, em sua dimensão simbólica e icônica, e com ele, a metáfora, como possível portadora de um saber.

\section{A SUBVERSÃO RENITENTE DO LIXO SEMIOLÓGICO: OS SINTOMAS HISTÉRICOS}

Como é sabido, Freud teve uma formação acadêmica médica, interessando-se desde o começo pela atividade científica de pesquisa, sobretudo em fisiologia. Este traço, apesar de todo o desenvolvimento posterior da psicanálise e da metapsicologia, nunca o abandonou. Como clínico, espanta-se com a estranheza dos sintomas histéricos. Como pode haver sintomas no corpo dos quais o paciente realmente sofra e para os quais não haja uma explicação anatômica? E como, sob hipnose, estes sintomas desaparecem ou podem ser mesmo induzidos em outras pessoas?

\begin{abstract}
A histeria é uma neurose no mais estrito sentido da palavra - quer dizer, não só não foram achadas alterações perceptíveis no sistema nervoso, nessa doença, como também não se espera que qualquer refinamento das técnicas de anatomia venha a revelar alguma dessas alterações (Freud, 1888, p. 79).
\end{abstract}

Além disto, os sintomas são mutáveis - não apenas no mesmo paciente, mas no próprio desenrolar histórico-social (Van Den Bergh, 1965) ${ }^{4}$ - exagerados, e colocam em xeque a própria habilidade do médico, podendo este fazer muitos "milagres" ou mostrar-se totalmente impotente (Freud, 1888). Enveredando na pesquisa e tratamento da histeria, Freud vai se aproximando cada vez mais da importante questão dos conflitos virtuais do paciente e da linguagem na formação de tais sintomas.

Em seus Estudos sobre Histeria (Freud, 1893a) cita que a simbolização exerce papel fundamental na formação do sintoma, dando como exemplo a neuralgia de Cecily:

Estava curioso em descobrir se também a neuralgia viria a ter uma causa psíquica. Quando comecei a evocar a cena traumática, a paciente viu-se de volta a um período de grande irritabilidade para com o marido. Descreveu uma conversa que tivera com ele e a observação dele que ela sentira como um áspero insulto. De súbito levou a mão à bochecha, soltou um grande grito de dor e exclamou: "foi como uma bofetada no rosto". Com isso cessaram tanto a dor como o acesso (Freud, 1893a , p. 227)

Ainda que o próprio Freud tenha reconhecido depois a exceção da "facilidade" do caso de Cecily, faz-se notar aqui a abertura da possibilidade de se pensar o papel da linguagem no sintoma e, nela, o

4 Isto é, os sintomas mudam com as épocas, tendo, portanto, uma influência cultural. Van den Bergh deu a esta característica o nome de 'metablética'. 
papel exercido pela metáfora (Zanello \& Martins, prelo). Vemos que a metáfora foi tomada literalmente (desmetaforicizada), inscrita no corpo da paciente (ela se mostra). Apenas quando ela pode metaforicizar a metáfora, por exemplo, transformando-a numa comparação, é que o sintoma se esvai (recupera-se o "como se" da metáfora, sem o qual não há metáfora). Freud cita ainda outros exemplos interessantes, como a dor entre as sobrancelhas de que a paciente se queixa e da qual se cura, ao lembrar-se e falar do "olhar penetrante" da avó. Ele nos diz:

Minha observação de Frau Cecily $M$. proporcionou-me a oportunidade de fazer uma coletânea regular de tais simbolizações. Todo um grupo de sensações físicas que ordinariamente seriam consideradas por causas orgânicas eram, no seu caso, de origem psíquica, ou pelo menos possuíam um significado psíquico. Uma série específica de suas experiências foram acompanhadas por uma sensação de apunhalamento na região do coração (significando "apunhalou-me até o coração"). A dor que ocorre na histeria em que pregos são cravados na cabeça, era, sem dúvida, explicada no seu caso como uma dor relacionada com o pensamento ("Alguma coisa me entrou na cabeça"). Dores dessa espécie eram logo dissipadas, quando os problemas em jogo eram esclarecidos. Junto com a sensação de uma "aura" histérica na garganta, quando aquela sensação surgia após um insulto, encontrava-se o pensamento "terei que engolir isto". (Freud, 1893a , p. 230)

E logo após comenta:

Ao tomar uma expressão verbal literalmente, e ao sentir a "punhalada no coração" ou a "bofetada na face" após uma observação desatenta como um fato real, o histérico não toma liberdade com as palavras, mas simplesmente revive as sensações às quais a expressão verbal deve sua justificativa. (Freud, 1893a, p. 230)

Freud vai sugerir então que a histeria é o fóssil da linguagem, pois, ao restaurar o significado original das palavras, retrata-as em seu corpo: "Assim, aqui como em outras ocasiões, a neurose, acompanhando os usos da linguagem, toma as palavras no seu sentido original e significativo; parecendo utilizá-las em sentido figurado, está na realidade simplesmente devolvendo a elas seu sentido primitivo" (Freud, 1908, p. 180).
O que se transforma em dor física é o sofrimento psíquico, que, desta forma, é evitado. Freud nos diz, assim, que o sintoma tem sentido e se relaciona com a experiência do paciente; é uma solução de compromisso entre o que foi recalcado e o Eu. A determinação do sintoma se dá por uma "relação simbólica" (Freud, 1893b) entre a causa determinante e o próprio sintoma, tendo a linguagem aí um papel decisivo: "é como se houvesse a intenção de expressar o estado mental através de um estado físico; o uso linguístico constitui uma ponte para o cumprimento desse objetivo" (Freud, 1893b, p. 263). No uso linguístico encontraríamos muitas vezes metáforas, trocadilhos, associações pelo som (Freud, 1893a)... A linguagem não apenas se relaciona diretamente com o sintoma, como mediadora, mas é através dela mesma, na plena qualificação da fala, que ocorre a cura. A metáfora exerce aí papel fundamental, apontando na associação livre do paciente, quando fala além daquilo que intenciona, quanto faz mediação entre o sentir (estésis), ancorado no corpo próprio, pulsional, e o falar (ou o não falar, mostrando-se no sintoma). O proferimento de metáforas será, portanto, plenamente qualificado nesta prática clínica que se abre ao pathos 5 .

Vê-se assim quanto a clínica iniciada por Freud passa a se distanciar do proceder semiológico médico. Isto parece ter assustado o próprio autor:

Nem sempre fui psicoterapeuta. Como outros neuropatologistas, fui preparado para empregar diagnósticos locais e eletroprognose, e ainda me surpreende que os históricos de casos que escrevo pareçam contos e que, como se poderia dizer, eles se ressintam do ar de seriedade da ciência (Freud, 1893a, p. 209).

Estaria o médico se aproximando do poético? Pensamos que sim e que tal aproximação não se deu sem consequências importantíssimas para o repensar da própria clínica. O sintoma histérico foi, desta maneira, pedra angular neste processo. Ao se abrir ao pathos Freud reabre a possibilidade de qualificação da metáfora, e ao requalificar o sintoma como metáfora incrustada no corpo pulsional, vê-se obrigado a um alargamento da clínica, reconsiderando justamente o

Quanto às funções que a metáfora pode exercer na clínica, bem como a função metafórica do terapeuta/analista, ver: Zanello, V. (2007). A metáfora no trabalho clínico. Guarapari: Editora Exlibris; Zanello, V. (2007). Metáfora e transferência. Psicologia: Reflexão e Crítica, 20(1), 132-137. 
pathos e afirmando uma clínica especificamente "psi"a psicanálise. Destarte, o que era lixo semiológico na prática médica era, de fato, como fez questão de apontar, um príncipe de ópera disfarçado de mendigo (Freud, 1893a).

\section{REFERÊNCIAS}

Apel, K. O. (2000). Transformações da Filosofia 1: Filosofia Analítica, Semiótica, Hermenêutica (P. A. Soethe , Trad.). São Paulo: Edições Loyola. (Original publicado em 1973).

Aristóteles (1991). La Métaphysique. Inglaterra: Agora. (Originalmente publicado no século IV a.c.).

Aristóteles (2005). Órganon. Bauru: EDIPRO. (Originalmente publicado no século IV a.c.).

Aristóteles (1999). Poética. Os Pensadores. São Paulo: Abril (Originalmente publicado no século IV a.c.).

Descartes, R. (2000). Discurso sobre o método (Pietro Nassetti, Trad.). São Paulo: Martin Claret. (Originalmente publicado em 1637).

Foss (1965). Encyclopedia of Poetry and Poetics. Princeton University Press: Princeton.

Freud, S. (1974). Histeria (J. Salomão Trad.). Edição Standard Brasileira das Obras Psicológicas Completas (Vol. 1, pp.77100). Rio de Janeiro: Imago. (Original publicado em 1888).

Freud, S. (1974). Estudos sobre a Histeria (J. Salomão Trad.). Edição Standard Brasileira das Obras Psicológicas Completas (Vol.2). Rio de Janeiro: Imago. (Original publicado em 1893a).

Freud, S. (1974). Sobre o mecanismo psíquico dos fenômenos histéricos (J. Salomão Trad.). Edição Standard Brasileira das Obras Psicológicas Completas (Vol. 3, pp. 35-52). Rio de Janeiro: Imago. (Original publicado em 1893b).

Freud, S. (1974). Caráter e erotismo anal (J. Salomão Trad.). Edição Standard Brasileira das Obras Psicológicas Completas (Vol. 9, pp.171-181). Rio de Janeiro: Imago. (Original publicado em 1908).

Garcia-Roza. L. A. (2001). Palavra e verdade na filosofia antiga e na psicanálise. Rio de Janeiro: Jorge Zahar.

Marques, M. P. (1990). O Caminho Poético de Parmênides. São Paulo: Edições Loyola.

Martins, F. (2003). Psicopathologia II - Semiologia Clínica. Brasília: Laboratório de Psicopatologia e Psicanálise/ABRAFIPP.

Meunier, J.P. (1994). Les téories de la communication. Em Département de Communication/ UCL (Org). Recherches en
Communication - Métaphores (I) (pp. 71-92). Louvain-laNeuve : UCL.

Meyer, M. (2000). Prefácio. Em Aristóteles; Retórica das Paixões (pp. XVII-LI). São Paulo: Martins Fontes.

Ricoeur, P. (2000). A Metáfora Viva (D. D. Macedo, Trad.). São Paulo: Martins Fontes. (Original publicado em 1975).

Rorty, R. (1994). A filosofia e o espelho da natureza (Antônio Trânsito, Trad.). Rio de Janeiro: Relume Dumará. (Originalmente publicado em 1979).

Rorty, R. (1999). Ensaios sobre Heidegger e outros- Escritos Filosóficos 2 (M. A. Casanova, Trad.). Rio de Janeiro: RelumeDumará. (Original publicado em 1991).

Van Den Bergh, J. H. (1965). Metablética (F. Van der Water, Trad.). São Paulo: Mestre Jou. (Original publicado em 1956).

Vergote, A. (1981). Le corps. Em Morren, L. (Org). La Signification $d u$ corps (pp.07-33). Louvain-la-Neuve: Cabay.

Verhaegen, P. (1994). Image, diagramme et métaphore - A propos de l'icône chez C.S. Peirce. Dans Département de Communication/ UCL (Org). Recherches en Communication - Métaphores (I) (pp. 19-47). Louvain-la-Neuve : UCL.

Vernant, P. (1973). Mito e pensamento entre os gregos (H. Sarian, Trad.). São Paulo: Difel. (Original publicado em 1965).

Wittgenstein, L. (1995). Algumas Observações sobre Forma Lógica (D. Dal' Agnol, Trad.). Revista Manuscrito, 2 (XVIII), 39-47.

Wittgenstein, L. (1991). Investigações Filosóficas (J. C. Bruni, Trad.). Os Pensadores. São Paulo: Nova Cultural. (Original publicado em 1953).

Wittgenstein, L. (1994). Tractatus Logico-Philosophicus (L. H. Santos, Trad.). São Paulo: Edusp. (Original publicado em 1921).

Zanello, V. (2007). A metáfora no trabalho clínico. Guarapari: Editora Exlibris.

Zanello, V. (2007). Metáfora e transferência. Psicologia: Reflexão e Crítica, 20(1), 132-137.

Zanello, V. \& Martins, F. Associação livre e Metáfora. Em V. L. Besset, \& H. F. Carneiro, (Orgs.) (no prelo). Psicopatologia e Psicanálise (ANPEPP/GT Psicopatologia e Psicanálise). Rio de Janeiro: Garamond.

Recebido em 23/11/2008 Aceito em 04/11/2009

Endereço para correspondência : Valeska Zanello. SQS 203, B1. F Apt. 106, CEP 70233060, Brasília-DF, Brasil.

E-mail:valeskazanello@uol.com.br. 